\title{
Air quality monitoring program at the Port of Busan, South Korea: 3D measurements
}

\author{
JEONGWON KANG ${ }^{1}$, SANGMIN HYUN ${ }^{2}$, SEONYOUNG
} PARK $^{1}$, YUNJI KIM ${ }^{1}$

${ }^{1}$ Korean Seas Geosystem Research Unit, Busan 49111, South Korea, jwkhang7@kiost.ac.kr

${ }^{2}$ Marine Environmental Research Center, Busan 49111, South Korea

This study for the air quality monitoring program at the Port of Busan, which is the largest port and located at the southeastern tip of South Korea, specializes a real-time measurement of pollutants with a multi-rotor drone. The drone carries sensors (PM1, 2.5, 10, temperature, humidity, wind speed and wind direction) that monitor the vertical PM distributions, then it could calculate the particle mass flux density $\left(\mu \mathrm{g} / \mathrm{s} / \mathrm{m}^{2}\right)$, together with a wind direction vertically. This air monitoring project began in February 2020, in order to understand the PM behaviors across the Port of Busan and to identify the effects of ship emissions on the PM occurrance, together with a ground-based observations.

Preliminary data of the PM concentrations could be obtained up to $150 \mathrm{~m}$ (GPS altitude, a.s.1), which is probably whin the atmospheric mixed layer due to no variations of the vertial PM concentrations, and further showed a similar concentration level from the ground-based observation. After rain event, the PM concentrations decreased due to probably wash out of coarse particles ranged of PM2.5 to 10 relatively. But the PM concentrations increased again to levels before the rain event, indicating that the measurements after rain event are helpful to understand the PM transport and occurrance at a sampling site; this result is more comprehensive for interpretation of air quality data and for use in special studies, such as air quality modelling applications. In addition, the results of 3D measurements (drone and ground-based) on PM concentrations are approached by using the statistical methodology. 